\title{
Prevalence and Factors Affecting the Development of Active-Tb among HIV-Positive Patients at Shashemene Referral Hospital, Shashemene, West Arsi, Ethiopia
}

\author{
Hunduma Dinsa Ayeno* and Tesfaye Negesa Liche
}

Department of Pharmacy, College of Medicine and Health Sciences, Ambo University, Ambo, Ethiopia

\begin{abstract}
Tuberculosis (TB) is a communicable bacterial disease commonly caused by Mycobacterium tuberculosis, which mainly affects the pulmonary system. TB is the principal single reason of decease in the setting of AIDS, comprising of $26 \%$ of AIDS-related deaths, $99 \%$ of which occur in unindustrialized countries like Ethiopia.

Objective: To determine the prevalence and determinants of active TB infection among HIV positive patients.

Method: This study was conducted at Shashemene Referral Hospital in HIV clinic. The study design was retrospective cross-sectional study. This study was conducted in HIV clinic from February 2017-March 2017. In this study a systematic sampling technique was adopted for selecting a representative sample.

Results: A total of 309 HIV infected patient medical records containing required information were reviewed. Out of 309 HIV infected patients $48.5 \%$ were males. Majority of them were in the age range $18-54$ y (86.1\%). Out of 309 HIV infected patients, $77(24.9 \%)$ developed active TB, while $232(75.1 \%)$ would not and $218(70.6 \%)$ and 55 (17.8\%) were at WHO HIV clinical stage III and IV respectively. Factors like divorced, widowed, unemployment, illiterate, CD4<200 cells $/ \mathrm{mm}^{3}$ were independently associated with TB development in HIV infected patients.

Conclusions: In conclusions, the prevalence of tuberculosis in this study was found to be high among divorced, widowed, unemployment, illiterate, CD4<200 cells $/ \mathrm{mm}^{3}$. Therefore Health information about risk factors for TB infection and early diagnosis and treatment of TB infection are very important for HIV patients in the study area.
\end{abstract}

Keywords: Active-TB; Prevalence; TB/HIV co-infection

\section{Abbreviations}

AFB: Acid Fast Bacilli; AIDS: Acquired Immune Deficiency Syndrome; AOR: Adjusted Odds Ratio; ART: Anti-Retroviral Therapy; AU: Ambo University; AUERB: Ambo University Electoral Review Board; CD4: Cluster of Differentiation 4; COR: Crude Odds Ratio; EPTB: Extra Pulmonary Tuberculosis; FMOH: Federal minister of Health; HBC: High Burden Countries; HIV: Human Immunodeficiency Virus; MDRTB: Multi Drug Resistance Tuberculosis; OPD: Outpatient Department; PTB: Pulmonary Tuberculosis; PLWHIV: People Living with Human Immune-deficiency Virus; RVI: Retro Viral Illness; SPSS: Statistical Package of Social Science; SRH: Shashemene Referral Hospital; TB: Tuberculosis; WHO: World Health Organization.

\section{Introduction}

Tuberculosis (TB) is an infectious bacterial disease commonly caused by Mycobacterium tuberculosis, which mainly affects the lung parenchyma [1]. It is spread from one person to another person via droplets of nuclei from the throat and lungs of people with the active TB infection. In immune competent people, infection with Mycobacterium TB often has no symptoms, since the person's immune system acts to suppress the bacteria [2].

$\mathrm{TB}$ is among the leading causes of mortality for people living with HIV (PLWHIV) which comprises $25 \%$ of all causes of deaths [3]. HIV and TB respectively, are the first and second leading causes of death worldwide due to a single infectious agent $[1,4]$. HIV increases the progression of latent Mycobacterium tuberculosis to active disease and also raises the frequency of occurrence of TB [5]. PLWHIV may also be more vulnerable to TB infection $[3,6]$. Both TB and HIV lead to the main problem of infectious disease in impoverished countries [7].
Due to the common immune defence mechanisms between the two diseases, TB is a leading avertable cause of mortality among people living with HIV and vice versa [8-10]. Most of these deaths occur in low income countries like Ethiopia [10]. TB-HIV co-infections carry actual diagnostic and therapeutic challenges and exert enormous burden on health care systems in African and Asian countries with large populations of co-infected individuals. In the single host the two pathogens, $M$. tuberculosis and HIV, complement one another, hastening the worsening of immunological functions and resulting in untimely death if untreated $[9,10]$. Fourteen million people globally are estimated to be co-infected [10]. According to World Health Organization report, Ethiopia ranks seven amongst the 22 high affliction countries with TB and HIV infection in the world [4,6]. Likewise, TB has been found to aggravate HIV infection [4,6]. Various lines of confirmation indicate that inborn errors of immunity, as well as genetic polymorphisms, have an influence on vulnerability to TB and HIV [6].

Tuberculosis (TB) is transmissible and airborne. TB is one of the main public health dangers, competing with the HIV as the reason of death due to infectious diseases globally $[9,10]$. Although a decreasing

*Corresponding author: Hunduma Dinsa Ayeno, Lecturer and Head Department of Pharmacy, College of Medicine and Health Sciences, Ambo University, Ambo Ethiopia, Tel: +251112363164; E-mail: dhunduma@gmail.com

Received July 24, 2018; Accepted August 22, 2018; Published August 31, 2018 Citation: Ayeno HD, Liche TN (2018) Prevalence and Factors Affecting the Development of Active-Tb among HIV-Positive Patients at Shashemene Referra Hospital, Shashemene, West Arsi, Ethiopia. J Bioanal Biomed 10:100-104. doi:10.4172/1948-593X.1000215

Copyright: $\odot 2018$ Ayeno HD, et al. This is an open-access article distributed under the terms of the Creative Commons Attribution License, which permits unrestricted use, distribution, and reproduction in any medium, provided the original author and source are credited. 
trend in TB incidence, prevalence and mortality has been reported over the 10 years, eradication of the disease worldwide is still out of reach, and huge resource investment is still required. TB is a povertyrelated disease which disproportionately upsets the poorest, the most susceptible and disregarded population groups wherever it happens [11]. Increasing access to diagnosis and care, the basic requirements in the fight against $\mathrm{TB}$, are mainly challenging in these population groups [12]. Information is limited on the proportion of TB, HIV and TB/HIV co-infection in the study area in Ethiopia [13].

Based on the 2014 WHO report, the prevalence of TB is 211 per 100,000 of the population. About $13 \%$ of all new TB cases are also HIV co-infected. Moreover, Ethiopia is one of the high TB/HIV and multidrug resistant TB (MDR TB) burden countries. Among TB patients with known HIV status, about $11 \%$ were HIV co-infected $[6,14]$. TB-HIV co-infections pose particular diagnostic and therapeutic challenges and put forth enormous burden on health care systems. Information is limited on the proportion of TB, HIV and TB/HIV co-infection in the study area in Ethiopia. Also, various studies done nationally could not reflect the real TB/HIV situation in Shashemene area due to methodological variation $[13,14]$.Therefore the aim of this study was to estimate the prevalence and factors associated with active-TB infection among HIV positive patients at Shashemene referral Hospital West Arsi, Ethiopia.

\section{Methods and Materials}

\section{Study area}

This study was conducted at Shashemene referral Hospital HIV clinic. Shashemene Referral Hospital is found in Kuyera town about $238 \mathrm{~km}$ south of the capital city, Addis Ababa. It is one of the most experienced hospitals of the region with more than $50 \mathrm{y}$ of service for the population of the area which is currently estimated to be 2.1 million people. It was built by missionaries in 1942 and in 1968 upgraded to governmental general hospital. In 1999 the hospital upgraded to referral hospital. Nowadays the hospital encompasses 12.2 hectares of land with a total of 242 employees with the bed number of 167 .The hospital on average serves 254 patients per day. Study was conducted from February to March 2017 by using data from September 2013 to March 2017.

\section{Study design}

Retrospective cross-sectional study design was used to conduct the research at HIV clinic of Shashemene referral hospital.

\section{Target population}

- $\quad$ All adult HIV positive patients.

\section{Study population}

- All patients those attended HIV clinic at SRH from September 2013 to March 2017

\section{Sample size determination}

Sample size was calculated by single population proportion formula using $95 \%$ confidence level, $5 \%$ degree of precision and $25 \%$ proportion of TB/HIV co- infection. The minimum sample size (n) required, for a very large population $(\mathrm{N}>10,000)$ is:

$\mathrm{n}=(\mathrm{Za} / 2)^{2} \mathrm{p}(1-\mathrm{p}) / \mathrm{w} 2=1.96^{2} \times(0.25) \times(0.75) /(0.05)^{2}=288 ;$ by adding $10 \%$ allowance for missing data it became 317 .

\section{Sampling techniques}

- A systematic sampling method was adopted for selecting a representative sample.

- Patients' cards were selected randomly using their ART unique identification number.

\section{Eligibility criteria}

Inclusion criteria: All adult Human Immunodeficiency Virus (HIV) sero-positive patients.

Exclusion criteria: 1) Cards of the Patients those develop active TB before HIV infection is confirmed. 2) Patients with age of less than 18-years-old.

\section{Study variables}

- Dependent variables: TB/HIV co-infection.

- Independent variables: Patient demographics (age, sex, education status, religion, residence, ethnicity, CD4 count).

\section{Data collection procedure}

Separated data collection forms were designed on which data from the patient cards were collected. The forms were filled by data collectors recruited from nurses working in the HIV clinic.

\section{Data processing and analysis}

Descriptive statistics such as frequencies and percentage were summarized and presented in the form of tables and graphs. Odds ratio and $95 \%$ confidence interval was used to check significant association between dependent and independent variables using Bivariate and Multivariate analysis by logistic regression model. In all cases, P-value $<0.05$ was considered to be significant. All analyses were done using statistical package for social sciences (SPSS) version 16.

\section{Ethical consideration}

Ethical clearance was obtained from Ambo University, College of Medicine and Health Sciences, Department of pharmacy. Then, letter of permission was presented to AUERB. Verbal informed consent was obtained from medical director and health professional working in this clinic prior to patients card review after the purpose of the study was explained to them. Confidentiality of the information was assured by using medical record numbers.

\section{Results}

A total of $317 \mathrm{HIV}$ infected patient medical records were selected by systematic random sampling. However only $309 \mathrm{HIV}$ positive patients had complete information and were reviewed. Out of 309 HIV infected patients $48.5 \%$ were males. Majority of them were in the age group of 18-54 years (86.1\%) (Table 1). Out of 309 HIV infected patients 77 (24.9\%) developed active TB (Figure 1) and 218 (70.6\%) and $55(17.8 \%)$ were at WHO HIV clinical stage III and IV respectively. Other clinical profiles of the study participants were displayed in Table 2 .

\section{Discussion}

HIV infection is the single most important fueling agent for everincreasing prevalence of tuberculosis. Moreover, TB is a well-recognized opportunistic infection in patients with HIV/AIDS. The prevalence of TB among study participants was 77 (24.9\%) (Figure 1). The result of this study is slightly higher than study done in south Ethiopia, Hawassa University, from a total of 499 HIV/AIDS positive patients 91 (18.2) of the study participants were found to have tuberculosis [15] and lower than study done at Jimma University, Southwest Ethiopia [16]. 
Citation: Ayeno HD, Liche TN (2018) Prevalence and Factors Affecting the Development of Active-Tb among HIV-Positive Patients at Shashemene Referral Hospital, Shashemene, West Arsi, Ethiopia. J Bioanal Biomed 10:100-104. doi:10.4172/1948-593X.1000215

\begin{tabular}{|c|c|c|c|}
\hline No. & Variables & Sub-variables & Frequency (\%) \\
\hline \multirow{3}{*}{1} & \multirow{3}{*}{ Age } & $18-54$ & $266(86.1)$ \\
\hline & & $>55$ & $43(13.9)$ \\
\hline & & Total & $309(100)$ \\
\hline \multirow{3}{*}{2} & \multirow{3}{*}{ Sex } & Male & $147(47.6)$ \\
\hline & & Female & 162(52.4) \\
\hline & & Total & $309(100)$ \\
\hline \multirow{5}{*}{3} & \multirow{5}{*}{ Educational status } & Illiterate & $73(23.6)$ \\
\hline & & Primary & $89(28.8)$ \\
\hline & & Secondary & $93(30.1)$ \\
\hline & & Tertiary & $54(17.5)$ \\
\hline & & Total & $309(100)$ \\
\hline \multirow{7}{*}{4} & \multirow{7}{*}{ Occupational status } & Unemployed & $31(10.0)$ \\
\hline & & Merchant & $44(14.2)$ \\
\hline & & Farmer & $50(16.2)$ \\
\hline & & Government Employee & $73(23.6)$ \\
\hline & & Students & $70(22.7)$ \\
\hline & & Others & $41(13.3)$ \\
\hline & & Total & $309(100)$ \\
\hline \multirow{5}{*}{5} & \multirow{5}{*}{ Marital status } & Married & $154(49.8)$ \\
\hline & & Unmarried & $69(22.3)$ \\
\hline & & Divorced & $35(11.3)$ \\
\hline & & Widow & $51(16.5)$ \\
\hline & & Total & $309(100)$ \\
\hline \multirow{3}{*}{6} & \multirow{3}{*}{ Residence } & Urban & $210(60)$ \\
\hline & & Rural & $99(32)$ \\
\hline & & Total & $309(100)$ \\
\hline
\end{tabular}

Table 1: Socio demographic characteristics of adult HIVIAIDS positive patients at Shashemene Referral Hospital, (n=309), September 2013-March 2017.

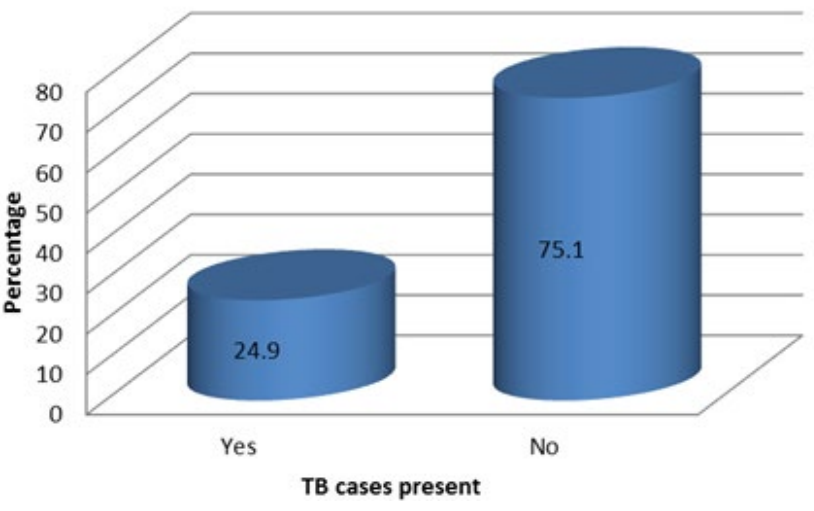

Figure 1: Percentage of active TB cases among HIV positive patients at Shashemene Referral Hospital ( $n=309)$, September 2013-March 2017.

This variation may be due to difference in study area, study period and incidence of the diseases. Pediatrics was not included due to different pharmaceutical preparation, pharmacokinetics and difficulty of adherence in this age group.

The most important associated factor for development of TB in HIV/ AIDS patients is the immunological state of the person. Maintaining the $\mathrm{CD} 4$ cell level as high as possible in patients with advanced disease helps the person to have low risk of infection or re-activation of tubercle bacilli. In this study, In multivariate logistic regression analysis, married was 0.058 times less likely to develop TB than the Divorced $(\mathrm{AOR}=0.058,95 \% \mathrm{CI}(0.015,0.221), \mathrm{P}=0.000)$ and 0.172 times less

\begin{tabular}{|c|c|c|c|}
\hline No. & Variables & Variable category & $\begin{array}{c}\text { Frequency } \\
\text { (\%) }\end{array}$ \\
\hline \multirow{5}{*}{1} & \multirow{5}{*}{ WHO HIV clinical stage } & Stage 1 & $78(25.2)$ \\
\hline & & Stage 2 & $72(23.3)$ \\
\hline & & Stage 3 & $86(27.8)$ \\
\hline & & Stage 4 & $73(23.6)$ \\
\hline & & Total & $309(100)$ \\
\hline \multirow{5}{*}{2} & \multirow{5}{*}{ CD4 level at HIV diagnosed } & $<200$ & $106(34.3)$ \\
\hline & & $201-350$ & $77(24.9)$ \\
\hline & & $351-500$ & $54(17.5)$ \\
\hline & & $>500$ & $72(23.3)$ \\
\hline & & Total & $309(100)$ \\
\hline \multirow{3}{*}{3} & \multirow{3}{*}{ TB Developed } & Yes & $77(24.9)$ \\
\hline & & No & $232(75.1)$ \\
\hline & & Total & $309(100)$ \\
\hline \multirow{3}{*}{4} & \multirow{3}{*}{ TB Prophylaxis } & Yes & $7(2.3)$ \\
\hline & & No & $302(97.7)$ \\
\hline & & Total & $309(100)$ \\
\hline \multirow{4}{*}{5} & \multirow{4}{*}{ Functional status } & Working & $188(60.8)$ \\
\hline & & Ambulatory & $102(33)$ \\
\hline & & Bedridden & $19(6)$ \\
\hline & & Total & $309(100)$ \\
\hline
\end{tabular}

Table 2: Clinical profiles of adult HIVIAIDS positive patients at Shashemene Referal Hospital, (n=309), September 2013-March 2017.

likely to develop TB than Widow (AOR $=0.172,95 \% \mathrm{CI}(0.054,0.172)$, $\mathrm{P}=0.003$ ) displayed (Table 3 ). Farmers were 0.152 times less likely to develop TB than Unemployment $(\mathrm{AOR}=0.152,95 \% \mathrm{CI}: 0.032,0.182$, $\mathrm{P}=0.017)$ and those who had CD4 cell count less than 200 cells $/ \mathrm{mm}^{3}$ at HIV diagnosed were 5.803 times ( $\mathrm{AOR}=5.803$, 95\% CI: 1.778, 18.972, $\mathrm{P}=0.004)$ more likely to develop TB than those who had CD4 count between 200 and 350 cells $/ \mathrm{mm}^{3}$ while having CD4 cell count less than 200 cells $/ \mathrm{mm}^{3}$ at HIV diagnosed were 40.381 times more likely to develop TB than those who had CD4 count between 351 and 500 cells/ $\mathrm{mm}^{3}$. Study participants with secondary School educational level were 3.64 times $(\mathrm{AOR}=3.64, \mathrm{CI}: 1.187,11.129, \mathrm{P}=0.024)$ and tertiary School educational level 4.01 times $(\mathrm{AOR}=4.01, \mathrm{CL}$ : $1.144,14.072, \mathrm{P}=0.030)$ more likely to develop TB than illiterate as shown in Table 3.

This finding is similar with study conducted in Southwest Ethiopia that shows factors independently associated with active TB: After adjustment for potential confounders were a low level of education (OR=2.8; 95\% CI: 1.1, 7.1) [17] and study done in China shows from significant variables low CD4 count were risk factor for active TB in people living with HIV/AIDS [18]. The study conducted in Burkina Faso indicates that the TB risk factors among PLWHAs were from a rural area $(p<0.001)$ and not educated $(p=0.047)$ which is similar to the current study, But being male is not associated with HIV related TB in the current study unlike that of study done in Burkina Faso [19].

\section{Limitations of the Study}

The obtained data was based on recorded information in the medical records of patients. So accuracy of the findings of this study depends on the accuracy of the registered information. Therefore, information bias may be occurred in the registered data. In this study there may be some risk factors that were not taken into account, such as duration of HIV, living environment, smoking and contact with tuberculosis in family.

\section{Conclusion and Recommendation}

There was high prevalence of TB infection among HIV patients in 
Citation: Ayeno HD, Liche TN (2018) Prevalence and Factors Affecting the Development of Active-Tb among HIV-Positive Patients at Shashemene Referral Hospital, Shashemene, West Arsi, Ethiopia. J Bioanal Biomed 10:100-104. doi:10.4172/1948-593X.1000215

\begin{tabular}{|c|c|c|c|c|c|c|c|c|c|c|c|}
\hline \multirow[t]{2}{*}{ Variables } & \multirow[t]{2}{*}{ Variables category } & \multicolumn{2}{|c|}{ TB present } & \multicolumn{2}{|c|}{$95.0 \%$ C.I. } & \multirow[t]{2}{*}{ COR } & \multirow[t]{2}{*}{ P-value } & \multicolumn{2}{|c|}{ 95.0\% C.I. } & \multirow[t]{2}{*}{ AOR } & \multirow[t]{2}{*}{ P-value } \\
\hline & & Yes & No & Lower & Upper & & & Lower & Upper & & \\
\hline \multirow{4}{*}{ Marital status } & Married & 17 & 137 & & & & & & & & \\
\hline & Unmarried & 15 & 54 & 0.21 & 0.96 & 0.45 & 0.038 & 0.17 & 1.31 & 0.48 & 0.151 \\
\hline & Divorced & 17 & 18 & 0.06 & 0.3 & 0.13 & 0 & 0.02 & 0.22 & 0.06 & $0.000^{*}$ \\
\hline & Widowed & 28 & 23 & 0.05 & 0.22 & 0.1 & 0 & 0.05 & 0.55 & 0.17 & $0.003^{*}$ \\
\hline \multirow{6}{*}{ Occupation } & Farmer & 7 & 43 & & & & & & & & \\
\hline & Government employee & 12 & 61 & 0.3 & 2.27 & 0.83 & 0.713 & 0.37 & 5.39 & 1.4 & 0.621 \\
\hline & Student & 22 & 48 & 0.14 & 0.91 & 0.36 & 0.032 & 0.18 & 2.26 & 0.64 & 0.489 \\
\hline & Others & 7 & 34 & 0.25 & 2.47 & 0.79 & 0.686 & 0.3 & 5.36 & 1.27 & 0.744 \\
\hline & Unemployed & 20 & 11 & 0.03 & 0.27 & 0.09 & 0 & 0.03 & 0.71 & 0.15 & $0.017^{*}$ \\
\hline & Merchant & 9 & 35 & 0.21 & 1.87 & 0.63 & 0.408 & 0.22 & 4.1 & 0.95 & 0.949 \\
\hline \multirow{4}{*}{ Educational status } & Illiterate & 33 & 40 & & & & & & & & \\
\hline & Primary & 17 & 72 & 1.73 & 7.05 & 3.49 & 0 & 0.97 & 9.08 & 2.96 & 0.057 \\
\hline & Secondary & 15 & 78 & 2.09 & 8.81 & 4.29 & 0 & 1.19 & 11.13 & 3.64 & $0.024^{*}$ \\
\hline & Tertiary & 12 & 42 & 1.31 & 6.36 & 2.89 & 0.009 & 1.14 & 14.07 & 4.01 & $0.03^{*}$ \\
\hline \multirow{4}{*}{ HIV clinical Stage } & I & 3 & 75 & & & & & & & & \\
\hline & II & 3 & 69 & 0.18 & 4.71 & 0.92 & 0.92 & 0.01 & 4.31 & 0.22 & 0.321 \\
\hline & III & 19 & 67 & 0.04 & 0.5 & 0.14 & 0.002 & 0.02 & 4.91 & 0.29 & 0.392 \\
\hline & IV & 52 & 21 & 0.01 & 0.06 & 0.02 & 0 & 0.01 & 1.16 & 0.07 & 0.063 \\
\hline \multirow{4}{*}{ CD4 count at HIV diagnosis } & $<200$ & 62 & 44 & & & & & & & & \\
\hline & $200-350$ & 11 & 66 & 4.01 & 17.83 & 8.46 & 0 & 1.77 & 18.97 & 5.8 & $0.004^{*}$ \\
\hline & $351-500$ & 2 & 52 & 8.47 & 158.42 & 36.64 & 0 & 4.25 & 383.62 & 40.38 & $0.001^{*}$ \\
\hline & $>500$ & 2 & 70 & 11.48 & 211.87 & 49.32 & 0 & 0.72 & 149.88 & 10.36 & 0.086 \\
\hline
\end{tabular}

Table 3: Factors associated with tuberculosis among HIVIAIDS positive patients at Shashemene Referral Hospital, ( $n=309$ ), September $2013-M a r c h$ 2017.

*=statistically significant

the study area. The prevalence of TB among study participants was 77 (24.9\%). The most important factors independently associated with active TB in this hospital were unemployment; divorce and widow, CD4 level less than 200 cells $/ \mathrm{mm}^{3}$ are HIV diagnosed and illiteracy of study participants. Health information about risk factors for TB infection and early diagnosis and treatment of TB infection are very important for HIV patients in the study area. Furthermore, the health office should open for TB/HIV co-infection units in the hospitals.

\section{Declarations}

\section{Ethics approval and consent to participate}

Verbal informed consent was obtained from medical director and health professional working in this clinic prior to patients card review after the purpose of the study was explained to them. Confidentiality of the information was assured by using medical record numbers

\section{Funding}

Ambo University is the source of fund for data collection and analysis of this research.

\section{Acknowledgements}

The financial support of Ambo University is acknowledged. We would like to acknowledge data collectors and the staff of HIV clinic of Shashemene Referral Hospital for their cooperation during the data collection.

\section{References}

1. WHO (2010) Tuberculosis - The Essentials. (4 ${ }^{\text {th }}$ edn.), Geneva, Switzerland.

2. Stop TB (2014) Partnership: Talking Points-TB/HIV. Geneva, Switzerland.

3. WHO (2017) Global tuberculosis report 2017. World Health Organization, Geneva Switzerland.

4. WHO (2014) Global Tuberculosis Report 2014. World Health Organization, Geneva, Switzerland.

5. Federal Ministry of Health Ethiopia (2008) Tuberculosis, Leprosy and TB/HIV Prevention and Control Programme Manual. ( $4^{\text {th }}$ edn), Addis Ababa, Ethiopia.

6. World Health Organization (2015) WHO Country Cooperation Strategy 20122015. Ethiopia. WHO, Regional Office for Africa.

7. WHO media center (2015) Tuberculosis fact sheet. WHO, Geneva.

8. WHO (2010) Priority research questions for TB/HIV in HIV prevalent and resource limited settings. Geneva, Switzerland.

9. WHO (2012) Policy on collaborative TB/HIV activities: guidelines for national programmes and other stakeholders. Geneva, Switzerland.

10. WHO (2008) WHO Three 'l's meeting: intensified case finding, isoniazid preventive therapy and TB infection control for people living with HIV. Geneva, Switzerland.

11. WHO (2011) Guidelines for intensified tuberculosis case-finding and isoniazid preventive therapy for people living with HIV in resource-constrained settings. Department of HIVIAIDS, Stop TB department, Geneva, Switzerland.

12. WHO (2015) Country office for Ethiopia. HIVIAIDS progress, Geneva, 
Citation: Ayeno HD, Liche TN (2018) Prevalence and Factors Affecting the Development of Active-Tb among HIV-Positive Patients at Shashemene Referral Hospital, Shashemene, West Arsi, Ethiopia. J Bioanal Biomed 10:100-104. doi:10.4172/1948-593X.1000215

\section{Switzerland.}

13. Federal Democratic Republic of Ethiopia Ministry of Health (2015) Health sector development programme IV. Global tuberculosis report, Geneva.

14. United States Government agency for international development (USAID) (2015) The Twin epidemics: HIV and TB co-infection.

15. Desalegn K, Bekele S, Yadassa F (2017) Prevalence of Tuberculosis Coinfection and Associated Factors among HIV Patients Attending Anti-Retroviral Therapy at Jimma University specialized Teaching Hospital, South West Ethiopia. J Med Phys Biophys 29: 1-6.

16. Fekadu S, Teshome W, Alemu G (2015) Prevalence and determinants of Tuberculosis among HIV infected patients in Hawassa University, south
Ethiopia. J Infect Dev Ctries 9: 898-904.

17. Taha M, Deribew A, Tessema F, Assegid S, Duchateau L, et al. (2009) Risk Factors of Active Tuberculosis in People Living with HIVIAIDS in Southwest Ethiopia: A Case Control Study, Southwest Ethiopia. Ethiop J Health Sci 21: 131-139.

18. Cui Z, Lin M, Nie S, Lan R (2017) Risk factors associated with Tuberculosis (TB) among people living with HIVIAIDS: A pair-matched case-controlstudy in Guangxi, China. PLoS One 12: e0173976.

19. Méda ZC, Sombié I, Sanon OW, Maré D, Morisky DE, et al. (2013) Risk Factors of Tuberculosis Infection Among HIVIAIDS Patients in Burkina Faso. AIDS Res Hum Retroviruses 29: 1045-1055. 